\title{
Early recognition of coeliac disease through community pharmacies: a proof of concept study
}

\author{
Heidi Urwin $^{2} \cdot$ David Wright $^{1}\left(\right.$ D $\cdot$ Michael Twigg $^{1} \cdot$ Norma McGough $^{2}$
}

Received: 20 January 2017/ Accepted: 31 January 2017/Published online: 10 February 2017

(C) Springer International Publishing 2017

\section{Dear Editor,}

In the publication of our proof of concept study [1], we incorrectly described the point of care test Simtomax ${ }^{\circledR}$ as measuring both total IgA and IgA tTG antibodies. The test detects total IgA, recommended by NICE, and both $\operatorname{IgA}$ and IgG antibodies against deamidated gliadin peptides, ensuring those with IgA deficiency are identified, reducing the risk of false negative results. The revised NICE guideline for coeliac disease acknowledges the rising evidence of point of care tests and as a result removed the statement 'do not use point of care tests' from their previous guidance [2].

\section{References}

1. Urwin H, Wright D, Twigg M, McGough N. Early recognition of coeliac disease through community pharmacies: a proof of concept study. Int J Clin Pharm. 2016;38:1294-300.

2. National Institute for Health and Care Excellence. NICE guideline NG20; Coeliac disease; recognition, assessment and management 2015 [cited 2016 Aug 3] Available from: https://www.nice.org.uk/ guidance/ng20.
David Wright

d.j.wright@uea.ac.uk

1 School of Pharmacy, University of East Anglia, Norwich NR4 7JT, UK

2 Coeliac UK, 3rd Floor, Apollo Centre, Desborough Avenue, High Wycombe, Bucks HP11 2QW, UK 